\title{
RISK ASSESSMENT ALAT PRODUKSI GULA CANE KNIFE PADA STASIUN GILINGAN DI PT. $X$
}

\author{
RISK ASSESSMENT TOOL PRODUCTION OF SUGAR CANE KNIFE \\ GRINDING STATION PT. X
}

\author{
Bramantio Andananta Chrisna Putra \\ PT. Wilmar Group \\ E-mail: bramantio2506@gmail.com
}

\begin{abstract}
Industrial development in Indonesia is growing rapidly. This should be balanced with the application of good HA safety risk management to workplace hazard risks. As in PT. X Lumajang Regency, in its production process has great potential hazard. One of them is in the cane knife tool at Gilingan Station that has been damaged in operation and has an employee accident impact. Therefore, to prevent the occurrence of recurrence of risk assessment, including hazard identification, risk assessment and hazard control. The purpose of this study is to conduct risk assessment using the method of failure mode effect analysis (FMEA) on the Cane Knife production process tool in PT. X Lumajang District. This research is descriptive research. The target of this research is sugar production process at PT. X with the informant is 1 person Quality Control $(Q C), 1$ person production operators and 1 supervisor. The results show that there are 6 (six) failure modes that occur in the cane knife tool. Based on the Risk Priority Number (RPN), the highest failure mode occurs is a broken clutch string. While for risk control, quite enough. This is because there have been risk control efforts include technical control that is the installation of safety valve, administrative control is the application of SOP for workers and personal protective equipment. But for personal protective equipment only safety helmet, for other companies do not provide. The conclusion that can be drawn is the need for better risk control, especially on the damage that occurred on the clutch rope broken tool cane knife.
\end{abstract}

Keywords: cane knife, failure mode effect analysis, risk assessment

\begin{abstract}
ABSTRAK
Pembangunan industri di Indonesia semakin berkembang pesat. Hal ini tentu harus diimbangi dengan penerapan manajemen risiko K3 yang baik agar risiko bahaya di tempat kerja dapat dikendalikan. Seperti halnya di PT. X Kabupaten Lumajang, dalam proses produksinya mempunyai potensi bahaya yang besar. Salah satunya pada alat cane knife di Stasiun Gilingan yang pernah mengalami kerusakan saat beroperasi dan berdampak kecelakaan kerja bagi pekerja. Oleh karena itu, untuk mencegah kejadian tersebut terulang perlu adanya risk assessment, meliputi identifikasi bahaya, penilaian risiko dan pengendalian bahaya. Tujuan dari penelitian ini adalah melakukan risk assessment menggunakan metode failure mode effect analysis (FMEA) pada alat proses produksi Cane Knife di PT. X Kabupaten Lumajang. Penelitian ini adalah penelitian deskriptif. Sasaran penelitian ini adalah proses produksi gula di PT. X dengan informanya adalah 1 orang Quality Control (QC), 1 orang operator produksi dan 1 orang supervisor. Hasil penelitian menunjukkan terdapat 6 (enam) mode kegagalan yang terjadi di alat Cane Knife. Berdasarkan nilai Risk Priority Number (RPN), mode kegagalan terjadi yang paling tinggi adalah tali kopling putus. Sementara untuk pengendalian risiko, tergolong cukup. Hal ini dikarenakan telah terdapat upaya pengendalian risiko meliputi pengendalian teknik yaitu pemasangan safety valve, pengendalian administratif yaitu penerapan SOP bagi pekerja dan alat pelindung diri. Alat pelindung diri hanya safety helmet, untuk yang lainnya perusahaan tidak menyediakan. Kesimpulan yang dapat ditarik adalah perlu adanya pengendalian risiko yang lebih baik lagi terutama pada kerusakan yang terjadi pada tali kopling putus alat cane knife.
\end{abstract}

Kata kunci: cane knife, failure mode effect analysis, risk assessment

\section{PENDAHULUAN}

Pembangunan industri di Indonesia semakin pesat karena Indonesia adalah negara berkembang, seperti halnya negara berkembang yang lain, selalu identik dengan banyaknya industri. Adanya perkembangan industri yang berkembang pesat tentu memiliki dampak positif dan dampak negatif. Salah satu dampak positifnya adalah menyerap banyak 
tenaga kerja yang ada di Indonesia. Dampak negatif dari perkembangan industri adalah jika industri tersebut tidak melakukan pengendalian risiko yang efektif, sehingga dapat menyebabkan kecelakaan kerja dan mengancam keselamatan bagi pekerja. Menurut laporan terbaru International Labour Organization (ILO) membuktikan bahwa setiap hari rata-rata 6.000 meninggal dunia, setara dengan 1 orang setiap 15 detik atau 2,2 juta orang per tahun akibat sakit atau kecelakaan yang berkaitan dengan pekerjaan mereka (Pawesondra, 2016). Jumlah korban pria lebih banyak dua kali dibandingkan korban wanita karena kemungkinan besar pria paling banyak mengisi kuota angkatan kerja dan mengerjakan pekerjaan yang lebih berbahaya.

Kesehatan dan keselamatan kerja saat ini menjadi salah satu fokus utama di Indonesia. Hal ini dikarenakan masih tingginya angka kecelakaan kerja di Indonesia. Menurut Pradana (2013), Jamsostek menyebutkan bahwa sepanjang tahun 2009 telah terjadi 54.398 kasus kecelakaan kerja di Indonesia. Pemerintah merealisasikan dengan mengeluarkan Undang-Undang RI No. 1 Tahun 1970 tentang Keselamatan Kerja, Undang-Undang No. 3 Tahun 1992 tentang Jaminan Sosial Tenaga Kerja (Jamsostek), dan Peraturan Menteri Tenaga Kerja No Per.05/Men/1996 tentang Sistem Manajemen K3 (Soputan, 2014). Pengusaha menganggap bahwa menginvestasikan modal dalam masalah keselamatan kerja sangat merugikan karena program K3 memerlukan dana yang besar dan tidak memberikan keuntungan secara nyata dan langsung kepada perusahaan. Bagi karyawan masalah K3 tidak penting, karena selama dia bekerja tidak mengalami gangguan dan mendapatkan upah yang besar itu sudah cukup bagi karyawan dan yang terpenting adalah karyawan tersebut masih mendapatkan lapangan pekerjaan. Opini tersebut kurang tepat terhadap keselamatan kerja.

Penerapan program Keselamatan dan Kesehatan Kerja (K3) di suatu perusahaan sangatlah penting karena hal ini bertujuan untuk menciptakan suasana kerja yang nyaman dan aman untuk perusahaan, pekerja dan pengunjung/tamu yang memasuki wilayah perusahaan tersebut. Keselamatan kerja adalah keselamatan yang berhubungan dengan mesin, alat kerja, bahan dan proses pengolahan, tempat kerja dan lingkungan serta cara melakukan pekerjaan. Keselamatan kerja menyangkut segenap proses produksi dan distribusi baik barang dan jasa. Sampai saat ini masih banyak perusahaan yang mengabaikan masalah $\mathrm{K} 3$, sehingga terjadinya risiko kecelakaan kerja pada pekerjaan tidak bisa dihindari. Secara umum sasaran utama dari kecelakaan kerja adalah karyawan/operator.

Dari hasil identifikasi awal dengan menggunakan teknik wawancara dan review dokumen, diketahui bahwa di Pabrik Gula X terdapat banyak sekali risiko bahaya di bagian produksinya. Menurut pekerja bagian Quality Control (QC) dari Pabrik Gula X tersebut untuk masa giling tahun ini masih ada kejadian yang dapat merugikan pekerja dan tentu saja produksi tebu tersebut yaitu terjadi kerusakan roda gila sehingga roda gilanya lepas dan beterbangan di sekeliling pabrik. Oleh karena itu, perlu adanya risk assessment di Pabrik Gula $\mathrm{X}$ ini agar dapat mengetahui apa saja potensi risiko yang ada di proses produksi Pabrik Gula X. Adanya risk assessment tentu harapannya dapat mengurangi kejadian kecelakaan di tempat kerja dan meningkatkan produktivitas dari pekerja.

Risk assessment merupakan bagian dari manajemen risiko yang bertujuan untuk mengelola aspek dan dampak dari Keselamatan dan Kesehatan Kerja (K3). Menurut Siahaan (2007), risk assessment meliputi 3 aspek pokok yaitu identifikasi bahaya, penilaian risiko dan evaluasi risiko yang dapat dijadikan sebagai bahan evaluasi bahaya untuk dapat menentukan tingkat risiko dan tindakan bahaya yang akan dilakukan untuk mengurangi dan meminimalisir terjadinya kecelakaan kerja bagi pekerja. Identifikasi risiko adalah proses untuk mengetahui adanya suatu bahaya, sehingga mampu dilakukan estimasi risiko yang kemudian ditentukan prioritas untuk pengendalian terhadap bahaya tersebut dengan tujuan untuk memperkecil semua faktor risiko yang dapat mengganggu keselamatan dan kesehatan kerja (K3) tenaga kerja.

Risk assessment merupakan salah satu solusi untuk mengurangi dan menimimalisir terjadinya kecelakaan kerja. Setelah melakukan risk assessment harapannya adalah penerapan manajemen risiko $\mathrm{K} 3$ berkaitan dengan bahaya dan risiko yang ada di tempat kerja yang dapat menimbulkan kerugian bagi perusahaan (Nalhadi, 2017). Manajemen K3 pada dasarnya mencari dan mengumpulkan kelemahan operasional yang memungkinkan terjadinya kecelakaan (Anwar, 2014).

Salah satu metode dalam melakukan risk assessment adalah Failure Mode Effect Analysis (FMEA). FMEA adalah suatu prosedur yang terstruktur dan tersistematis untuk mengidentifikasi bahaya dan melakukan pencegahan sebanyak mungkin suatu mode kegagalan (failure mode). 
Suatu mode kegagalan adalah sesuatu yang termasuk dalam kegagalan/kecacatan, kondisi di luar batas yang telah ditentukan atau perubahan hasil produk yang dapat menyebabkan produk tersebut kehilangan fungsi. Terdapat dua tipe FMEA yaitu, FMEA desain dan FMEA proses. FMEA desain pengamatan difokuskan pada desain produk, sedangkan FMEA proses pengamatan difokuskan pada kegiatan proses produksi. Metode yang diterapkan pada penelitian ini adalah FMEA proses, karena pengamatan hanya dilakukan pada kegiatan proses produksi yang sedang berlangsung (Puspitasari, 2014).

Pembuatan FMEA bertujuan untuk mengidentifikasi dan menilai risiko yang berhubungan dengan potensi kegagalan (Iswanto, 2013). Potensi kegagalan adalah kondisi hilangnya fungsi alat produksi di bawah kondisi yang dinyatakan. FMEA dikatakan sebagai tindakan before the event karena FMEA berusaha untuk mengeliminasi dan mengurangi kemungkinan gagal dari penyebab, sehingga mencegah kegagalan tidak terulang lagi di masa mendatang (Badariah dkk, 2012).

FMEA dalam penelitian ini memberikan bobot penilaian berupa nilai Risk Priority Number (RPN) atau penyebab kegagalan produk sehingga dapat diketahui permasalahan yang harus diselesaikan terlebih dahulu. RPN digunakan untuk menaksir risiko berdasarkan tiga kriteria, Severity (S), Occurrence (O) dan Detection (D). Angka RPN merupakan hasil dari rating Severity, Occurrence dan Detection. Menurut Nilamsari (2016), nilai RPN yang tinggi akan membantu memberikan pertimbangan untuk tindakan korektif pada setiap mode kegagalan.

Beberapa metode risk assessment yang ada, namun metode FMEA merupakan metode yang sering digunakan dalam melakukan pengelolaan risiko daripada metode yang lain. Hal ini dikarenakan FMEA dapat memprioritaskan masalah yang ada dan dapat memberikan cara untuk meminimalisir terjadinya masalah tersebut.

\section{METODE}

Berdasarkan sifatnya penelitian ini termasuk dalam penelitian deskriptif yang memiliki tujuan memberikan gambaran secara objektif terhadap suatu keadaan dengan cara mendeskripsikan nya. Berdasarkan metode pengumpulan data, penelitian ini termasuk dalam penelitian observasional. Penelitian ini dilakukan di PT. X Desa Kaliboto Lor,
Kecamatan Jatiroto, Kabupaten Lumajang, terletak 180 KM dari Surabaya dan 24 KM dari Kabupaten Lumajang, Jawa Timur. Yang menjadi responden penelitian ini berjumlah 3 orang yang terdiri dari 1 orang operator Quality Control (QC), 1 orang operator produksi dan 1 orang supervisor.

Variabel dalam penelitian adalah penilaian risiko dengan menganalisis angka Severity, Occurrence dan Detection. Setelah muncul angka di setiap variabel akan dikalikan dan muncul nilai Risk Priority Number (RPN). RPN adalah indikator kekritisan untuk menentukan tindakan koreksi yang sesuai dengan mode kegagalan. Pengumpulan data dilakukan setelah peneliti menjelaskan Penjelasan Sebelum Persetujuan (PSP) dan Informed Consent.

Data diperoleh dari data primer dan data sekunder. Data primer dilakukan dengan cara observasi dan wawancara. Observasi akan dilakukan dengan mengamati mesin yang beroperasi di PT. X. Wawancara dilakukan kepada operator Quality Control, operator produksi dan Supervisor. Wawancara ini bertujuan untuk mendapatkan informasi mengenai proses produksi, bahaya dari proses produksi tersebut dan pengendalian yang telah dilakukan. Data sekunder diperoleh dari data sekunder yang sudah ada di perusahaan. Data tersebut meliputi sejarah perusahaan, visi dan misi perusahaan, kebijakan K3 dan proses produksi gula di PT. X.

Instrumen yang digunakan adalah berupa lembar observasi dan lembar wawancara. Lembar observasi menggunakan lembar Failure Mode Effect Analysis. Hasil dari observasi dan wawancara akan dianalisis melalui beberapa tahapan, yaitu identifikasi bahaya, penilaian risiko, dan pengendalian risiko. Tahapan awal dalam melakukan risk assessment adalah identifikasi bahaya. Identifikasi bahaya dilakukan untuk mengetahui bahaya dan risiko di setiap proses produksi di PT. X.

Setelah melakukan identifikasi bahaya tahapan selanjutnya adalah melakukan penilaian risiko. Penilaian risiko akan dilakukan secara kualitatif, menggunakan bentuk kata atau skala deskriptif untuk menjelaskan seberapa besar potensi risiko yang akan di ukur. Penilaian risiko pada FMEA ini berdasarkan dari hasil 3 indikator, yaitu Severity $(S)$, Occurrence $(O)$ dan Detection (D). Hasil dari 3 indikator tersebut kemudian akan dikali dan menghasilkan Risk Priority Number (RPN).

Nilai S merupakan sebuah penilaian pada tingkat keseriusan suatu efek atau akibat dari potensi kegagalan pada proses yang dianalisis. 
Tabel 1. Ranking Severity

\begin{tabular}{|c|c|c|}
\hline Ranking & Severity & Deskripsi \\
\hline 10 & $\begin{array}{l}\text { Berbahaya } \\
\text { tanpa } \\
\text { peringatan }\end{array}$ & $\begin{array}{l}\text { Kegagalan sistem yang } \\
\text { menghasilkan efek } \\
\text { sangat berbahaya }\end{array}$ \\
\hline 9 & $\begin{array}{l}\text { Berbahaya } \\
\text { dengan } \\
\text { peringatan }\end{array}$ & $\begin{array}{l}\text { Kegagalan sistem yang } \\
\text { menghasilkan efek } \\
\text { berbahaya }\end{array}$ \\
\hline 8 & Sangat tinggi & Sistem tidak beroperasi \\
\hline 7 & Tinggi & $\begin{array}{l}\text { Sistem beroperasi tetapi } \\
\text { tidak dapat dijalankan } \\
\text { secara penuh }\end{array}$ \\
\hline 6 & Sedang & $\begin{array}{l}\text { Sistem beroperasi } \\
\text { dan aman tetapi } \\
\text { mengalami penurunan } \\
\text { performa sehingga } \\
\text { mempengaruhi output }\end{array}$ \\
\hline 5 & Rendah & $\begin{array}{l}\text { Mengalami penurunan } \\
\text { kerja secara bertahap }\end{array}$ \\
\hline 4 & Sangat rendah & $\begin{array}{l}\text { Efek yang kecil pada } \\
\text { performa sistem }\end{array}$ \\
\hline 3 & Kecil & $\begin{array}{l}\text { Sedikit berpengaruh } \\
\text { pada kinerja sistem }\end{array}$ \\
\hline 2 & Sangat kecil & $\begin{array}{l}\text { Efek yang diabaikan } \\
\text { pada kinerja sistem }\end{array}$ \\
\hline 1 & Tidak ada efek & Tidak ada efek \\
\hline
\end{tabular}

Tabel 2. Ranking Occurrence

\begin{tabular}{|c|c|c|}
\hline Ranking & Occurrence & Deskripsi \\
\hline $10-9$ & Sangat tinggi & Sering gagal \\
\hline $8-7$ & Tinggi & $\begin{array}{l}\text { Kegagalan yang } \\
\text { berulang }\end{array}$ \\
\hline $6-4$ & Sedang & $\begin{array}{l}\text { Jarang terjadi } \\
\text { kegagalan }\end{array}$ \\
\hline $3-2$ & Rendah & $\begin{array}{l}\text { Sangat kecil terjadi } \\
\text { kegagalan }\end{array}$ \\
\hline 1 & Tidak ada efek & $\begin{array}{l}\text { Hampir tidak ada } \\
\text { kegagalan }\end{array}$ \\
\hline
\end{tabular}

Skala 1 sampai 10 digunakan untuk menentukan nilai severity. Skala penilaian severity menurut McDermott, dkk (2009) terdapat pada Tabel 1.

Nilai O pada analisis mencerminkan probabilitas atau peluang terjadinya kegagalan yang terjadi. Skala 1 sampai 10 digunakan untuk menentukan nilai occurrence. Ranking penilaian occurrence menurut McDermott (2009) terdapat pada Tabel 2.

Nilai D adalah peluang terjadinya kegagalan yang dapat terdeteksi sebelum terjadi. Skala 1 sampai 10 digunakan untuk menentukan nilai detection. Ranking penilaian detection menurut McDermott (2009) ditunjukkan pada Tabel 3.

Tabel 3. Ranking Detection

\begin{tabular}{|c|c|c|}
\hline Ranking & Detection & Deskripsi \\
\hline 10 & Tidak pasti & $\begin{array}{l}\text { Pengecekan akan selalu tidak mampu untuk mendeteksi penyebab potensial atau } \\
\text { mekanisme kegagalan dan mode kegagalan }\end{array}$ \\
\hline 9 & Sangat kecil & $\begin{array}{l}\text { Pengecekan memiliki kemungkinan "very remote" untuk mampu mendeteksi } \\
\text { penyebab potensial atau mekanisme kegagalan dan mode kegagalan }\end{array}$ \\
\hline 8 & Kecil & $\begin{array}{l}\text { Pengecekan memiliki kemungkinan "remote" untuk mampu mendeteksi penyebab } \\
\text { potensial atau mekanisme kegagalan dan mode kegagalan }\end{array}$ \\
\hline 7 & Sangat rendah & $\begin{array}{l}\text { Pengecekan memiliki kemungkinan sangat rendah untuk mampu mendeteksi } \\
\text { penyebab potensial kegagalan dan mode kegagalan }\end{array}$ \\
\hline 6 & Rendah & $\begin{array}{l}\text { Pengecekan memiliki kemungkinan rendah untuk mampu mendeteksi penyebab } \\
\text { potensial atau mekanisme kegagalan dan mode kegagalan }\end{array}$ \\
\hline 5 & Sedang & $\begin{array}{l}\text { Pengecekan memiliki kemampuan "moderate" untuk mendeteksi penyebab potensial } \\
\text { atau mekanisme kegagalan dan mode kegagalan }\end{array}$ \\
\hline 4 & Menengah ke atas & $\begin{array}{l}\text { Pengecekan memiliki kemungkinan "moderately high" untuk mendeteksi penyebab } \\
\text { potensial atau mekanisme kegagalan dan mode kegagalan }\end{array}$ \\
\hline 3 & Tinggi & $\begin{array}{l}\text { Pengecekan memiliki kemungkinan tinggi untuk mendeteksi penyebab potensial atau } \\
\text { mekanisme kegagalan dan mode kegagalan }\end{array}$ \\
\hline 2 & Sangat tinggi & $\begin{array}{l}\text { Pengecekan memiliki kemungkinan sangat tinggi untuk mendeteksi penyebab } \\
\text { potensial atau mekanisme kegagalan dan mode kegagalan }\end{array}$ \\
\hline 1 & Hampir pasti & $\begin{array}{l}\text { Pengecekan akan selalu mendeteksi penyebab potensial atau mekanisme kegagalan } \\
\text { dan mode kegagalan }\end{array}$ \\
\hline
\end{tabular}


HASIL

\section{Gambaran Umum Perusahaan}

PT. X tergabung dalam PT. Perkebunan Nusantara XI (Persero) yang merupakan Badan Usaha Milik Negara (BUMN), yang mengelola 16 Pabrik Gula, PT. X merupakan pabrik gula terbesar, baik dari kapasitas giling maupun luas area kerjanya.

\section{Kebijakan Keselamatan dan Kesehatan Kerja (K3) di PT. X}

Terdapat beberapa kebijakan K3 di PT. X. Kebijakan tersebut adalah mengendalikan risiko untuk mencegah terjadinya kecelakaan dan penyakit akibat kerja bagi karyawan dan tamu atau pengunjung, berkomitmen untuk mematuhi peraturan perundangan $\mathrm{K} 3$ dan persyaratan lainnya yang berlaku di Republik Indonesia, meningkatkan kinerja K3 secara berkesinambungan sebagai bagian dari kinerja perusahaan dan mewujudkan lingkungan kerja yang aman, nyaman dan efisien untuk mendorong produktivitas perusahaan serta kesejahteraan karyawan.

\section{Identifikasi Bahaya di PT. X}

Identifikasi bahaya di PT. X dilakukan dengan mengevaluasi proses untuk kemungkinan kegagalan dan untuk mencegah mereka dengan memperbaiki proses secara daripada bereaksi terhadap efek samping setelah kegagalan telah terjadi. Tahapan melakukan identifikasi bahaya adalah dengan melakukan observasi dan wawancara Quality control dan operator produksi di PT. X. Identifikasi bahaya di PT. X ini menggunakan metode failure mode and effect analysis (FMEA). FMEA adalah metode identifikasi bahaya dengan cara membayangkan kerusakan apa yang terjadi pada mesin produksi atau gagal berfungsi dan melihat apa akibat yang ditimbulkan dari kegagalan mesin tersebut.

Berdasarkan hasil pengamatan yang dilakukan di PT. X, terdapat beberapa potensi kegagalan yang dapat terjadi pada suatu alat. Potensi kegagalan yang paling tinggi adalah pada alat cane knife pada Stasiun Gilingan, karena pada alat ini pernah terjadi dan tingkat kemungkinan terjadinya cukup tinggi. Terdapat beberapa kegagalan yang mungkin terjadi seperti Cane Knife tidak dapat beroperasi, mengalami overspeed, jalur uap tertutup, tali kopling putus, Gearbox tidak berjalan maksimal dan pipa metal terkelupas. Dampak yang diakibatkan dari kegagalan tersebut adalah proses produksi tidak lancar, ledakan, wheel pada Cane Knife pecah dan terbang ke area kerja dan Gearbox mengalami kerusakan.

\section{Penilaian Risiko Bahaya di PT. X}

Penilaian risiko adalah proses menilai besarnya risiko yang diterima berdasarkan hasil identifikasi bahaya yang dilakukan di PT. X. Penilaian risiko dilakukan dengan menentukan nilai prioritas mode kegagalan, ketiga indikator tersebut dikalikan dan menghasilkan RPN. RPN ini menunjukkan tingkat prioritas sebuah mode kegagalan yang diperoleh dari hasil analisis pada proses yang dianalisis. Semakin tinggi nilai RPN maka urutan prioritas perbaikan nya semakin tinggi. Nilai RPN dihitung dengan rumus Severity (S) x Occurrence (O) x Detection (D). Tabel penilaian risiko bahaya di PT. X terdapat pada tabel 4 .

\section{Pengendalian Risiko Bahaya di PT. X}

Tahap selanjutnya dari risk assessment adalah pengendalian risiko. Tahap ini diharapkan dapat mengurangi dan meminimalisir terjadinya mode kegagalan sehingga kecelakaan kerja pun dapat berkurang. Pengendalian yang sudah dilakukan di PT. $X$ adalah pengendalian teknis, pengendalian administratif dan Alat Pelindung Diri (APD).

Pengendalian teknis adalah pengendalian bahaya berupa melalui perbaikan desain, penambahan peralatan atau penambahan pengaman peralatan. Pengendalian teknis yang telah dilakukan di PT. X berupa pemasangan safety valve terhadap beberapa alat yang berfungsi untuk mengatur tekanan berlebih sehingga tidak terjadi ledakan atau kebakaran. Pengendalian administratif adalah pengendalian yang menggunakan sistem atau buku panduan untuk melakukan pengendalian risiko tersebut. Pengendalian administratif yang telah dilakukan di perusahaan ini adalah adanya SOP dalam pekerjaan, penerapan Permit to Work (PTW), pemeriksaan alat dan bahan sebelum melakukan proses produksi dan adanya rotasi kerja. Pengendalian yang terakhir adalah adanya Alat Pelindung Diri (APD) untuk pekerja. Alat Pelindung Diri yang disediakan oleh perusahaan hanya helm. Untuk alat pelindung diri yang lain seperti glove, masker dan safety shoes perusahaan tidak menyediakan untuk pekerja. 


\section{PEMBAHASAN}

\section{Identifikasi Bahaya}

Setiap mesin produksi memiliki potensi yang berbeda satu sama lain, oleh karena itu diperlukan identifikasi bahaya. Identifikasi bahaya di tempat kerja bertujuan meminimalkan kerugian akibat kecelakaan dan sakit, serta pencegahan kerugian akibat kecelakaan dan penyakit akibat kerja (Ghaisani, 2014). Untuk identifikasi bahaya yang dilakukan di PT. X ini, digunakan metode Failure Mode Effect Analysis (FMEA).

Tabel 4. Tabel FMEA Stasiun Gilingan di PT. X

\begin{tabular}{|c|c|c|c|c|c|c|c|c|}
\hline \multicolumn{3}{|c|}{ Process/Product: Stasiun Gilingan } & \multicolumn{3}{|c|}{ FMEA Process } & \multirow[b]{2}{*}{$\begin{array}{l}\text { Current } \\
\text { Controls }\end{array}$} & \multirow[b]{2}{*}{ Detection } & \multirow[b]{2}{*}{$\begin{array}{c}\text { Risk } \\
\text { Priority } \\
\text { Number } \\
\text { (RPN) }\end{array}$} \\
\hline Component & $\begin{array}{c}\text { Potential } \\
\text { Failure } \\
\text { Mode }\end{array}$ & $\begin{array}{c}\text { Potential Effect } \\
\text { of Failure }\end{array}$ & Severity & $\begin{array}{c}\text { Potential } \\
\text { Cause of } \\
\text { Failure }\end{array}$ & Occurrence & & & \\
\hline \multirow{6}{*}{$\begin{array}{l}\text { Cane Knife } \\
\text { (Untuk } \\
\text { memotong } \\
\text { dan } \\
\text { menyayat } \\
\text { tebu } \\
\text { menjadi } \\
\text { bagian } \\
\text { kecil) }\end{array}$} & $\begin{array}{l}\text { Cane } \\
\text { Knife } \\
\text { tidak } \\
\text { beroperasi/ } \\
\text { mati }\end{array}$ & $\begin{array}{l}\text { Produksi tidak } \\
\text { lancar }\end{array}$ & 3 & $\begin{array}{l}\text { Temperatur } \\
\text { oli panas dan } \\
\text { menyebabkan } \\
\text { suhu alat } \\
\text { menjadi } \\
\text { panas }\end{array}$ & 4 & $\begin{array}{l}\text { Control } \\
\text { room }\end{array}$ & 3 & 36 \\
\hline & $\begin{array}{l}\text { Over } \\
\text { Speed }\end{array}$ & 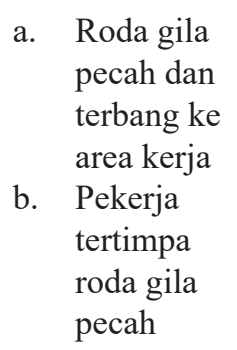 & 9 & $\begin{array}{l}\mathrm{RPM} / \text { putaran } \\
\text { terlalu tinggi }\end{array}$ & 6 & Atleter & 7 & 378 \\
\hline & $\begin{array}{l}\text { Jalur Uap } \\
\text { tertutup }\end{array}$ & Ledakan & 8 & $\begin{array}{l}\text { Valve } \\
\text { Governor } \\
\text { Lepas }\end{array}$ & 3 & $\begin{array}{l}\text { Valve } \\
\text { governor }\end{array}$ & 2 & 48 \\
\hline & $\begin{array}{l}\text { Tali } \\
\text { kopling } \\
\text { putus }\end{array}$ & 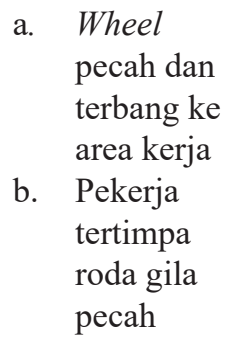 & 9 & $\begin{array}{l}\mathrm{RPM} / \text { putaran } \\
\text { terlalu tinggi }\end{array}$ & 6 & $\begin{array}{l}\text { Operator } \\
\text { di } \\
\text { tempat }\end{array}$ & 8 & 432 \\
\hline & $\begin{array}{l}\text { Gearbox } \\
\text { tidak } \\
\text { bekerja } \\
\text { maksimal }\end{array}$ & $\begin{array}{l}\text { Gear pompa } \\
\text { rusak dan } \\
\text { menghambat } \\
\text { produksi }\end{array}$ & 6 & $\begin{array}{l}\text { Tekanan / } \\
\text { aliran oli } \\
\text { tidak lancar }\end{array}$ & 2 & $\begin{array}{l}\text { Operator } \\
\text { di } \\
\text { tempat }\end{array}$ & 8 & 96 \\
\hline & $\begin{array}{l}\text { Pipa metal } \\
\text { terkelupas }\end{array}$ & $\begin{array}{ll}\text { a. Ledakan } \\
\text { b. Pekerja } \\
\text { terkena } \\
\text { efek } \\
\text { ledakan }\end{array}$ & 7 & $\begin{array}{l}\text { Pelumasan oli } \\
\text { metal tidak } \\
\text { lancar }\end{array}$ & 6 & $\begin{array}{l}\text { Operator } \\
\text { di } \\
\text { tempat }\end{array}$ & 7 & 294 \\
\hline
\end{tabular}


Berdasarkan hasil pengamatan yang dilakukan di PT. X, terdapat beberapa potensi kegagalan yang dapat terjadi pada suatu alat. Pada Cane Knife (CK), kegagalan yang dapat terjadi adalah Cane Knife tidak dapat beroperasi/mati sehingga menyebabkan proses produksi tidak lancar. Hal ini disebabkan karena temperatur oli panas sehingga alat menjadi panas dan Cane Knife akhirnya tidak dapat beroperasi/ mati. Kegagalan lain yang dapat terjadi adalah $O v e r$ Speed. Hal ini dapat terjadi disebabkan putaran roda gila pada Cane Knife terlalu cepat (melebihi RPM yang seharusnya). Efek yang ditimbulkan pun cukup berbahaya yaitu roda gila akan pecah dan terbang ke area kerja. Dampak lain yang dapat terjadi adalah pekerja tertimpa oleh roda gila tersebut.

Kegagalan yang dapat terjadi lagi pada Cane Knife adalah jalur uap yang tertutup. Karena Cane Knife beroperasi menggunakan tenaga uap turbin, jadi membutuhkan uap masuk untuk menggerakkan Cane Knife tersebut. Jika jalur uap tertutup, akan menyebabkan valve governor terlepas. Valve governor sendiri mempunyai fungsi sebagai mengatur jumlah uap yang masuk, sehingga jika valve governor terlepas maka tidak akan ada control lagi untuk uap yang masuk dan pada akhirnya efek yang terjadi adalah sebuah ledakan. Kegagalan selanjutnya yang dapat terjadi adalah tali kopling pada Cane Knife putus. Penyebabnya adalah RPM yang terlalu tinggi sehingga tali kopling menjadi putus. Efek yang ditimbulkan adalah wheel akan pecah dan terbang ke area kerja.

Kegagalan yang dapat terjadi selanjutnya adalah Gearbox yang tidak bekerja secara maksimal. Hal ini disebabkan oleh tekanan dan aliran oli yang tidak lancar, sehingga menyebabkan kinerja Gearbox menurun. Efek yang ditimbulkan adalah proses produksi terhambat. Kegagalan terakhir yang dapat terjadi adalah pipa metal pada Cane Knife terkelupas. Hal ini terjadi karena pelumasan oli metal tidak lancar. Sehingga akan menyebabkan pipa metal tersebut keropos dan kering. Jika hal ini terus terjadi akan menyebabkan ledakan. Dampak terhadap pekerja adalah dapat menyebabkan pekerja terbakar oleh ledakan yang timbul.

\section{Penilaian Risiko Bahaya di PT. X}

Setelah dilakukan identifikasi bahaya, selanjutnya adalah melakukan penilaian risiko bahaya pada PT. X. Penilaian risiko mempunyai tujuan untuk mengategorikan menjadi risiko kecil, risiko sedang, dengan risiko besar dan menyediakan data untuk membantu evaluasi dan penanganan risiko (Dharma, 2017).

Pada tahap ini dilakukan penilaian RPN bertujuan untuk mengetahui risiko yang potensial atau tingkat risiko yang paling kritis dengan memperhatikan risiko yang memiliki probabilitas kejadian yang tinggi dan memiliki konsekuensi atau dampak negatif yang besar serta kesempatan untuk memperbaiki dengan mendeteksi modus kegagalan sebelum terjadi dampak yang merugikan (Yessi, 2014). Nilai RPN didapatkan berdasarkan tingkat probability, severity, dan detection. Setelah mendapatkan ranking dari RPN dalam proses FMEA yaitu memberikan usulan perbaikan terhadap mode kegagalan yang telah di ranking urutan prioritas dari yang tertinggi. Usulan perbaikan tidak hanya diberikan pada nilai tertinggi, tetapi semua yang sudah teridentifikasi tetap diberikan usulan perbaikan sebagai bahan pertimbangan untuk perusahaan.

Berdasarkan hasil pengamatan yang dilakukan di PT. X, penulis akan memberikan perhatian khusus untuk Risk Priority Number (RPN) yang paling tinggi adalah terdapat pada Cane Knife yang mengalami kegagalan tali kopling putus. Angka RPN yang muncul adalah 432. Angka ini paling tinggi, karena dari Severity, Occurrence dan Detectabilty memang sangat parah. Tingkat severity tinggi karena jika memang hal ini terjadi akan menyebabkan bahaya yang cukup tinggi dan menyebabkan kecelakaan untuk para pekerja. Tingkat occurrence pun kegagalan termasuk kategori sedang dalam hal seberapa sering mengalami kegagalan. Tingkat detectabilty pun cukup tinggi angka nya karena memang tidak ada alat khusus untuk mendeteksi kegagalan untuk mengetahuinya dan hanya mengandalkan 1 operator. Perlu adanya pengendalian secara teknik agar potensi kegagalan ini dapat diminimalisir.

Nilai Risk Priority Number (RPN) yang tertinggi no 2 adalah pada Cane Knife yang mengalami kegagalan Overspeed pada poros penggerak. Angka RPN yang muncul adalah 378. Untuk nilai Severity adalah angka 9, karena memang mode kegagalan ini akan menghasilkan efek yang berbahaya. Untuk nilai Occurrence adalah angka 6, karena dari seberapa sering kejadiannya masih terbilang jarang terjadi kegagalan. Untuk nilai Detectability adalah angkat 7, karena pengecekan memiliki kemungkinan sangat rendah untuk mampu mendeteksi penyebab kegagalan tersebut. Hal ini juga perlu perhatian 
khusus, karena dengan hasil RPN yang tertinggi kedua menunjukkan bahwa potensi kegagalan tersebut juga perlu diminimalisir.

Nilai RPN yang tertinggi no 3 adalah pada Cane Knife yang mengalami kegagalan pipa metal terkelupas. Angka RPN yang muncul adalah 294. Nilai severity adalah 7, nilai occurrence 6 dan nilai detectability 7. Severity mendapat nilai 7 karena jika kegagalan terjadi alat tetap dapat beroperasi tetapi tidak dapat dijalankan secara penuh, sedangkan untuk occurrence mendapat nilai 6 karena kegagalan ini jarang terjadi. Untuk detectability, mendapat nilai 7 karena pengecekan memiliki kemungkinan sangat rendah untuk mampu mendeteksi penyebab kegagalan tersebut. Hal ini menunjukkan bahwa untuk alat deteksi potensi kegagalan tersebut masih kurang.

Nilai RPN selanjutnya adalah gearbox yang tidak dapat bekerja secara maksimal pada Cane Knife, angka yang muncul adalah 96. Angka Severity adalah 6 , karena jika terjadi kegagalan alat tetap beroperasi dan aman tetapi mengalami penurunan performa. Angka Occurrence adalah 2, karena sangat kecil terjadi kegagalan tersebut. Untuk detectability angkanya adalah 8 , karena pengecekan memiliki kemungkinan remote untuk mampu mendeteksi penyebab kegagalan tersebut. Hal ini menunjukkan bahwa angka Detection masih cukup tinggi dan perlu alat untuk mendeteksi bahwa gearbox dapat berjalan lancar.

Nilai RPN selanjutnya adalah tertutupnya pada jalur uap untuk menggerakkan Cane Knife, nilai yang muncul adalah 48. Nilai Severity adalah 8, karena alat tidak dapat beroperasi dengan baik. Angka Occurrence adalah 3, karena sangat kecil kejadian itu terjadi. Angka Detectability adalah 2, karena dari segi pengecekan kegagalan ini memiliki kemungkinan sangat tinggi untuk mendeteksi kegagalan yang terjadi.

Nilai RPN selanjutnya adalah pada alat Cane Knife yang mengalami kegagalan karena tidak dapat beroperasi dengan baik. Angka RPN adalah 36 . Nilai RPN untuk kegagalan ini memang yang paling kecil daripada yang lain, tapi hal ini tetap harus dikendalikan dengan baik agar proses produksi tidak terganggu dan hasil produksi juga sesuai dengan standar. Angka Severity adalah 3, karena dari tingkat keparahan hanya sedikit berpengaruh pada proses produksi. Angka Occurrence adalah 4, karena jarang terjadi kegagalan. Angka Detectability adalah 3, karena pengecekan memiliki kemungkinan tinggi untuk mendeteksi kegagalan yang ada.

\section{Pengendalian Risiko Bahaya di PT. X}

Menurut Ramli (2010), pengendalian risiko merupakan langkah penting dan menentukan dalam keseluruhan manajemen risiko, tahap ini sudah merupakan realisasi dari upaya pengelolaan risiko dalam perusahaan. Risiko yang telah diketahui harus dikelola dengan tepat, efektif dan sesuai dengan kondisi perusahaan. Pengendalian dapat lebih terfokus kepada bahaya potensial yang dinilai memiliki risiko tinggi sehingga lebih efektif dan efisien. Maka dari itu pengendalian merupakan proses tindak lanjut setelah dilakukannya penilaian bahaya.

Pengendalian risiko bahaya yang dilakukan di PT. X terhadap kegagalan tali kopling putus pada Cane Knife mengandalkan operator di tempat. Operator di tempat bertanggung jawab terhadap kegagalan ini, mereka hanya mengandalkan pengalaman dan SOP yang sudah pernah dilakukan oleh pekerja sebelumnya yang pernah berada di posisi tersebut. Hal ini tentu tidak baik, karena dengan risiko yang tinggi jika kegagalan ini terjadi perlu dilakukan sebuah pengendalian yang lain. Perlu adanya alat untuk mendeteksi gejala putusnya kopling tersebut dan perawatan rutin terhadap alat tersebut.

Pengendalian risiko bahaya yang mengandalkan para operator tidak hanya pada kegagalan tali kopling putus, di beberapa kegagalan juga hampir sama seperti itu. Seperti kegagalan Gearbox pada Cane Knife yang tidak berjalan secara maksimal dan pipa metal pada Cane Knife yang terkelupas. Semua kegagalan tersebut mengandalkan operator di tempat yang sudah dijelaskan SOP kerja dan berdasarkan pengalaman pekerja sebelumnya.

Pengendalian risiko bahaya pada Cane Knife yang mengalami kegagalan jalur uap tertutup yaitu adanya valve governor. Valve governor ini berfungsi untuk mengatur seberapa banyak uap yang masuk, jika uap yang masuk terlalu banyak akan menyebabkan valve governor ini rusak dan lepas. Rusak dan lepasnya valve governor ini berakibat fatal karena dapat terjadi ledakan pada Cane Knife tersebut. Operator pekerja juga sudah diberi SOP yang jelas jika terjadi kerusakan dan lepasnya valve governor ini. 


\section{SIMPULAN}

Berdasarkan hasil identifikasi bahaya di PT. $\mathrm{X}$ terdapat beberapa potensi kegagalan di Stasiun Gilingan pada alat Cane Knife, yaitu Cane Knife tidak dapat beroperasi, mengalami overspeed, jalur uap tertutup, tali kopling putus, Gearbox tidak berjalan maksimal dan pipa metal terkelupas. Hasil penilaian risiko bahaya di PT. X didapatkan bahwa nilai RPN yang tertinggi adalah pada mode kegagalan tali kopling putus pada Cane Knife. Pengendalian risiko di PT. X adalah pengendalian teknis, pengendalian administratif dan Alat Pelindung Diri (APD). Pengendalian teknis yang telah dilakukan di PT. X berupa pemasangan safety valve terhadap beberapa alat yang berfungsi untuk mengatur tekanan berlebih sehingga tidak terjadi ledakan atau kebakaran. Pengendalian administratif yang telah dilakukan di perusahaan ini adalah adanya SOP dalam pekerjaan, penerapan Permit to Work (PTW), pemeriksaan alat dan bahan sebelum melakukan proses produksi dan adanya rotasi kerja. Pengendalian yang terakhir adalah adanya APD untuk pekerja.

\section{DAFTAR PUSTAKA}

Anwar, F.N., Ida Farida, Agus Ismail., 2016. Analisis Manajemen Risiko Kesehatan dan Keselamatan Kerja (K3) pada Pekerjaan Upper Structure Gedung Bertingkat (Studi Kasus Proyek Skyland City-Jatinangor). Jurnal Konstruksi, [e-Jurnal] 13(1): pp. 1-13

Badariah, N., Surjasa, D., Trinugraha, Y., 2012. Analisis Supply Chain Risk Management Berdasarkan Metode Failure Mode Effects Analysis (FMEA). Jurnal Teknik Industri, [e-Jurnal] 2(2): p.110-118

Bayu D., A.A., Adnyana P., I.G., Parami D., A.A., 2017. Manajemen Risiko Keselamatan dan Kesehatan Kerja (K3) pada Proyek Pembangunan Jambuluwuk Hotel \& Resort Petitenget. Jurnal Spektran, [e-Jurnal] 5(1): pp. 1-9

Ghaisani, H., Nawawinetu, E.D., 2015. Identifikasi Bahaya, Penilaian Risiko dan Pengendalian Risiko Pada Proses Blasting di PT Cibaliung Sumberdaya, Banten. The Indonesian Journal of Occupational Safety and Health, [e-Jurnal] 3(1): pp. 107-116
Iswanto, A., Rambe, A.J.M., Ginting, E., 2013. Aplikasi Metode Taguchi Analysis dan Failure Mode and Effects Analysis (FMEA) untuk Perbaikan Kualitas Produk di PT. XYZ. Jurnal Teknik Industri USU, [e-Jurnal] 2(2): pp. 13-18

McDermott R. E., Mikulak R. J., Beauregard M. R., 2009. The Basics of FMEA. 2nd Edition. New York: Productivity Press

Nalhadi, A. And Rizaal, A., 2017. Identifikasi Bahaya Dan Penilaian Risiko K3 Pada Tindakan Perawatan \& Perbaikan Menggunakan Metode Hirarc (Hazard Identification And Risk Assessment Risk Control) Pada PT. X. Seminar Nasional Riset Terapan (SENASSET) Serang: pp. 281-286

Nilamsari, N., 2016. Manajemen Risiko K3. Surabaya: Airlangga University Press

Pawesondra, F.Y. 2016., Faktor-Faktor yang Berhubungan dengan Kejadian Kecelakaan Kerja pada Pekerja Pabrik di Bagian pembuatan Pintu PT Corinthian Industries Kabupaten Bogor Tahun 2016. Skripsi. Depok: Fakultas Kesehatan Masyarakat Universitas Indonesia

Pradana, R.K., Dwiyanti, E., 2013. Analisis Risiko Hydrogen Recovery Unit (HRU) dan Prioritas Risiko Kegagalan Komponen Pipa Gas Hidrogen di PT. Petrokimia. The Indonesian JOurnal of Occupational Safety and Health, [e-Jurnal] 2(1): pp. 10-19

Puspitasari, N.B., Martanto, A., 2014. Penggunaan FMEA dalam Mengidentifikasi Resiko Kegagalan Proses Produksi Sarung ATM (Alat Tenun Mesin) (Studi Kasus PT. Asaputex Jaya Tegal). Jurnal Teknik Industri, [e-Jurnal] 9(2): pp. 93-98

Ramli, S., 2010. Pedoman Praktis Manajemen Risiko dalam Perspektif K3. Jakarta: Dian Rakyat.

Siahaan, H., 2007. Manajemen Risiko. PT. Jakarta: Elex Media Komputindo

Sinaga, Y.Y., Cahyono, B.N., Trijoko W.A., 2014. Identifikasi dan Analisa Risiko Kecelakaan Kerja dengan Metode FMEA (Failure Mode And Effect Analysis) dan FTA (Fault Tree Analysis) di Proyek Jalan Tol Surabaya-Mojokerto. Jurnal Teknik Pomits, [e-Jurnal] 1(1): pp. 1-5

Soputan, G.E., Sompie, B.F. and Mandagi, R.J., 2014. Manajemen Risiko Kesehatan dan Keselamatan Kerja (K3) (Study kasus pada Pembangunan Gedung SMA Eben Haezar). Jurnal Ilmiah Media Engineering, [e-Jurnal] 4(4): pp. 229-238 